\title{
Towards Ontology-Based Design Science Research for Knowledge Accumulation and Evolution
}

\author{
Andy Nguyen \\ The University of Auckland \\ a.nguyen@auckland.ac.nz
}

\author{
Lesley Gardner \\ The University of Auckland \\ 1.gardner@auckland.ac.nz
}

\author{
Don Sheridan \\ The University of Auckland \\ d.sheridan@auckland.ac.nz
}

\begin{abstract}
The potential of design science research (DSR) to contribute to real-world problem solving and innovation has been considered as an opportunity for IS researchers to demonstrate the relevance and significance of DSR paradigm. While most DSR studies have been informed single design and development projects, future research needs to consider knowledge sharing and accumulation across multiple projects. This paper argues for combining the forces of design science research and ontology studies to foster knowledge creation and evolution. We propose a new approach to DSR by adopting ontology engineering as a knowledge sharing mechanism in which researchers assemble knowledge parts throughout the study. We develop a framework for understanding, conducting and evaluating ontology-based design science research, and then present the roadmap and guidelines for its conduct and evaluation. This paper concludes with a call for more collaborative efforts in design studies in IS research.
\end{abstract}

\section{Introduction}

In recent years, the Information Systems (IS) research community has made a significant progress to establish a sound foundation for high-impact design science research [14, 33, 38]. Turning to innovation, Design Science Research (DSR) is the common research method known for both producing innovative artefacts and contributing to the body of knowledge. One of the most critical challenges for DSR is to evaluate a designed artefact and knowledge contribution [10, 14]. However, the current way of sharing ideas and resources have been the main obstacles preventing greater collaboration and creative innovation. Recently, IS research community has heightened the need to establish a suitable mechanism and method for knowledge sharing and collaborative innovation [32, 35, 38]. It is time to foster knowledge accumulation and evolution from DSR studies [38].

In the fields of information systems and computer science, the branch of research used for knowledge management and sharing is usually referred to as ontology study or ontology engineering [21]. Although previous research has proposed comprehensive ontologies of academic studies to support scientific research [9, 30, 36, 37], formal research methodology and guidelines are not well established to promote scientific research based on ontologies.

This research was motivated by the unsuccessful search of current approaches to finding a formal method and guidelines for integrating ontology into design science research for knowledge accumulation and evolution. We found challenges in exploring the existing DSR artefacts and selecting appropriate instruments for conducting and evaluating DSR studies. Furthermore, we observe a need for an approach to formally structure the representation of DSR studies.

We argue for the usefulness of combining design science research and ontology engineering. In particular, we propose a new approach to DSR by adopting ontology engineering as a knowledge sharing mechanism. An ontology will act as the mainstay of a study in which researchers assemble knowledge parts throughout the study. Ontology mapping will not only enable effective and formal knowledge sharing between researchers and practitioners but also determine the significance of a particular DSR. Above all, the ontologies may reveal knowledge gaps for further research and innovation. Ontology-based design science research (ODSR) helps researchers throughout the process of analysis, artefact design, development, and evaluation. This paper provides a framework for understanding, conducting, and evaluating ontology-based design science research (ODSR) by incorporating the components adopted from both DSR framework by Hevner et al. [14] and the well-known methodology for building ontologies by Uschold and King [41]. 
The paper is structured as follows. First, section 2 reviews the design science literature in Information Systems (IS). The section introduces the diversity of design science in IS research, the nature of IS artefacts, their contributions, and current challenges of DSR. In section 3, ontology-based knowledge management for scientific research is introduced to facilitate the development of a research agenda for ontology-based design science research (ODSR). Section 4 proposes a framework for ODSR and, in section 5, ODSR roadmap and guidelines are introduced for conducting and evaluating ontology-based design science research. Section 6 demonstrates an example of the application of ODSR to discuss how this ontology-based approach could be used by DSR practitioners. Finally, we conclude with a call for further collaborative efforts to foster knowledge accumulation and evolution in IS design science research.

\section{Design science research in information systems}

\subsection{Overview of design science research}

Two main genres of research paradigms in the Information Systems discipline have been recognised as behavioural science and design science. Behavioural science research aims for theoretical development and verification whereas design science research focuses on delivering innovative artefacts in the context of extending the body of knowledge [13, 14]. Progressively IS practitioners have noticed the importance of blended features of two distinct IS research paradigms, behaviour science and design science [13].

Design science research originated from the field of engineering [14] and was introduced to IS research community in 1990 [26]. The mechanism involves diagnosing observed practical problems to establish research questions, solving the problems, developing artefacts to demonstrate the comprehensive solution, and evaluating the presented result. The designed artefacts are matched into the body of knowledge to offer additional understandings on the application or relevant area.

All research is established with underlying assumptions on the philosophical grounding around the research validity and the appropriateness of research methodology $[42,43]$. In order to conduct and evaluate research, it is important to acknowledge the existences of these philosophical assumptions, especially those related to reality, knowledge and value constructivism. This is also applied to design science research; thus,

Table 1: Philosophical grounding for IS research ([42], [45])

\begin{tabular}{|c|c|c|c|c|}
\hline \multicolumn{5}{|c|}{ Research Perspective } \\
\hline Assumptions & Positivist & Interpretivist & Critical & Design Science \\
\hline Ontology & $\begin{array}{l}\text { Single reality } \\
\text { related to natural } \\
\text { phenomena and } \\
\text { their properties } \\
\text { and relations. }\end{array}$ & $\begin{array}{l}\text { Multiple socially } \\
\text { constructed } \\
\text { realities }\end{array}$ & $\begin{array}{l}\text { Historically } \\
\text { constituted social } \\
\text { reality. }\end{array}$ & $\begin{array}{l}\text { Socio- } \\
\text { technological, } \\
\text { multiple, } \\
\text { contextually } \\
\text { situated alternative } \\
\text { realities. }\end{array}$ \\
\hline Epistemology & $\begin{array}{l}\text { Objective sensory } \\
\text { experience, } \\
\text { interpreted through } \\
\text { reason and logic }\end{array}$ & $\begin{array}{l}\text { Subjective } \\
\text { understandings } \\
\text { through the } \\
\text { meanings that } \\
\text { people assign }\end{array}$ & $\begin{array}{l}\text { Social critique, } \\
\text { whereby the } \\
\text { restrictive and } \\
\text { alienating } \\
\text { conditions of the } \\
\text { status quo are } \\
\text { brought to light }\end{array}$ & $\begin{array}{l}\text { Iterative } \\
\text { circumscription } \\
\text { offers new } \\
\text { knowledge, } \\
\text { constrained to } \\
\text { innovative and } \\
\text { developmental } \\
\text { artefacts } \\
\end{array}$ \\
\hline Axiology & $\begin{array}{l}\text { Universal facts, } \\
\text { prediction and } \\
\text { probability }\end{array}$ & $\begin{array}{l}\text { Hermeneutical and } \\
\text { phenomenological } \\
\text { understandings. }\end{array}$ & $\begin{array}{l}\text { Oppositions, } \\
\text { conflicts and } \\
\text { contradictions in } \\
\text { contemporary } \\
\text { society }\end{array}$ & $\begin{array}{l}\text { Innovation and } \\
\text { artefactual } \\
\text { impacts, extension } \\
\text { of knowledge } \\
\text { boundaries }\end{array}$ \\
\hline Common Methods & $\begin{array}{l}\text { Observation, } \\
\text { statistical, and } \\
\text { quantitative. }\end{array}$ & $\begin{array}{l}\text { Hermeneutical, } \\
\text { dialectical, and } \\
\text { qualitative. }\end{array}$ & $\begin{array}{l}\text { Action research, } \\
\text { case study. }\end{array}$ & $\begin{array}{l}\text { Development and } \\
\text { evaluation of } \\
\text { artefacts. }\end{array}$ \\
\hline
\end{tabular}


recent studies have attempted to define philosophical grounding for design science in IS research [23, 42].

In fact, the philosophical assumptions are noted to be implicit and clear most of the time for most people including readers and researchers in paradigmatic disciplines. However, philosophical grounding must be carefully considered in multi-paradigmatic or preparadigmatic communities such as Information Systems [42]. This is possibly due to the recognised differences in philosophical assumptions between natural sciences and social sciences. Natural sciences usually focus on observing a "single" reality and discovering new knowledge from the observed facts. Whereas social sciences often consider the human interpretation of their reality while obtaining new knowledge. In these cases, the reality is assumed to be socially constructed, and multiple realities can co-exist at the same time. Nevertheless, a number of social studies conducted based on observed facts, quantitative data and assumptions of a single knowable reality [45]. The philosophical grounding is independent from research methodology and disciplinary. As a result, several attempts have been made to classify and distinguish underlying philosophical assumptions [12, 27].

Table 1 describes philosophical grounding for design science and other research perspectives in IS research. Philosophical perspectives mostly differ in basic beliefs including ontology, epistemology, and axiology. Ontology is the research branch of metaphysics focusing on the nature of being, particularly what is the reality, its fundamental components, and derivative. Epistemology refers to the assumptions about the nature of knowledge and how knowledge can be obtained. Axiology is the study that explores the nature of values and how values align with individuals or groups. Based on assumptions about this metaphysics, research has categorised philosophical grounding into different research perspectives. One of the most commonly accepted classification has sorted philosophical assumptions into three main groups, namely positivist, interpretive and critical. Nevertheless, Vaishnavi and Kuechler [42] described the philosophical grounding for IS research to embrace socio-technological, multiple, contextually situated alternative realities. Recently, Iivari and Kuutti [17] has proposed a research agenda for critical design science research. There is acknowledged diversity in DSR that leads to different DSR genres $[32,35]$.

\subsection{Design science research genres}

The diversity of DSR has increasingly growth over the past decade. DSR studies are diverse in aspects of purpose, methodology, philosophical grounding and mental models. At present, there are five prototype genres identified in IS research: DSR Methodology, IS Design theory, Design-oriented IS research, Explanatory design theory, and Action design research [32] .

Design Science Research Methodology (DSRM): This genre focuses on the design and development of applicable artefacts which could have potential contributions to both theory and practice $[14,33]$. The DSRM artefact includes both not limit to systems, applications, frameworks and methods. DSRM includes processes of identifying a practical research problem, creating artefacts to address the problem and then to evaluate In addition, the process of design science research also needs to communicate the findings to appropriate audiences effectively [33]. As the core of DSRM is the creation of the artefact, its evaluation emphasizes on whether the artefact works as designed. Furthermore, the evaluation of DSRM may examine the artefact in different contexts. Although there are a variety of evaluation methods such as experiments, simulations, case studies, field studies or analytical studies, it does not require the evaluation of DSRM artefact to involve a formal process [32].

Action design research: A number of studies have noted the similarity between design science research and action research $[16,18,31]$. Action research (AR) refers to the reflective process of progressive problem solving or a study focusing on solving an immediate practical problem. The action research approach involves the collaboration between the researchers and other community practitioners to support problem identification and solving. Action research has been originally classified as a qualitative research method, yet Järvinen [18] suggests that action research seems much closer to design science approach. Similarly, Papas et al. [31] notes that, apart from the role of the artefacts, there is little to distinguish the two methodologies epistemologically. Conversely, Iivari \& Venable [16] argues that AR often differs from DSR regarding "paradigmatic assumptions of ontology, epistemology, methodology, and ethics, their research interests, and activities". Nevertheless, many papers that have been written on the comparison between AR and DSR agree that much similarity exists between the two research methods. As a result,

IS design theory: The focus of IS design theory is to communicate design theory independently from the applied science [32]. The term IS design theory (ISDT) is defined by Gregor \& Jones [19] as: "A design theory is something in an abstract world of man-made things, which also includes other abstract ideas such as algorithms and models". In general, ISDT is similar to a behavioural science theory [32]. An ISDT consists of eight fundamental components: purpose and scope, 
constructs, principles of form and function, artefact mutability, testable propositions, justificatory knowledge, principles of implementation, and expository instantiation [19]. Alturki et al. [3] suggested that any DSR should contribute to all these components of IS design theory. Developing IS design theories is essential to this genre of DSR while the instantiations in form of IT artefacts are not required. Similar to the evaluation of behavioural science theories, the proposition of hypotheses allows for the evaluation of IS theories by applying several analytical techniques.

Explanatory design theory: A design theory can be decomposed into two parts: a design practice theory and an explanatory design theory [5]. While a design practice theory guides the design process, an explanatory design theory offers a valuable explanation about the components of a solution and their usefulness. As a result, explanatory design theory (EDT) research focuses on design features and their relationship with the users and contexts. Different from DSRM and ADR, EDT considers the implementation of artefacts as means to results rather than things to be valued for themselves.

Design-oriented IS research: aims to design and develop advanced IS solutions and innovative concepts $[28,32,44]$. The utility for practice is an essential measure for DOIS research $[28,32]$. There are four key expectations for a DOIS research, namely abstraction, originality, justification, and benefit [28]. Abstraction refers to the usability of the artefact, i.e.each artefact must be applicable to a class of problems. Similar to any academic research, DOIS must demonstrate its originality, i.e. original contributions to the body of knowledge. Justification refers to the requirement that each DOIS artefact must be justified comprehensively and allow for validation. Finally, each DOIS must benefit relevant stakeholder groups, either immediately or in a long-term. DOIS consists of four main steps: analysis, design and development, evaluation, and diffusion.

\subsection{Contributions of design science research}

Research contributions reflect the values of any research, yet it is difficult for DSR researchers to justify their contributions to the field [10, 32]. Gregor \& Hevner [10] proposes the DSR knowledge contribution framework for evaluating the significance of an IS research following this approach. The framework comprises two main dimensions namely the solution maturity and application domain maturity. However, the growing diversity of DSR has challenged researchers to justify their research contributions and originality [32].
The profiling of background knowledge is essential for researchers to establish valid research questions as well as evaluate the research significance. This activity is also suggested as an important feature scholar's recommender systems [9]. We argue that a welldefined DSR methodology that supports the profiling of background knowledge would address the current challenges faced by DSR researchers. Such methodology would not only allow aid the evaluation of artefact and theoretical contributions, but also lead to system designs based on a better theoretical foundation.

\section{Ontology-based knowledge management for scientific research}

\subsection{Ontologies}

In general terms, ontologies are a formal and explicit representation of knowledge, a model of concepts and the relations among them in a specific domain [11]. While the term "ontology" has been confined to philosophical studies, it is now becoming increasingly widespread in the computer and information science communities. It also plays an important role in Artificial Intelligence (AI) and knowledge management research. Ontology has become a unique branch of scientific study on the nature of being, existence, the structure of being and their relationships [22, 25, 34]. At present, it been widely adopted in the research community that the formal definition of ontology is a shared conceptualization and formal specifications [39].

For the development and evaluation of information systems, the utilization of appropriate methodology and technology is essential. Nowadays, several methodologies and technologies exist and are widely applied in practice. Nevertheless, the selection of helpful instruments is a challenge for information systems development. For addressing this challenge, ontologies have been developed to provide a useful theoretical foundation for researchers to investigate a specific domain [22, 29]. Previous research has also suggested ontology-based development methodology for enterprise systems [1]. The ontology-based development methodology allows for identification of suitable system components and reduction of complexity of domain models.

\subsection{Scientific research based on ontologies}

The implementation of research ontologies with structured information and meta-data would help 
facilitate research process $[2,9]$. The ontologies offer an overview of the research fields and relevant technologies [7, 25, 46]. Moreover, the scientific research ontology can detect plagiarism [9] and aid literature review of relevant studies in a specific research area $[2,9]$. For instance, Almeida Biolchini et. al. [2] has proposed a scientific research ontology to support systematic review in software engineering. The ontology represents a template designed to support systematic reviews in Software Engineering. Furthermore, the study introduced the development of ontologies to describe knowledge in the field.

Broader in scope than Almeida Biolchini et. al.'s ontology [2], Ghanem, Mouloudi \& Mourchid [9] suggests a general ontology of academic publication to support scientific research. The ontology has three levels of distinguished utilities. The first utility level is to support researchers by providing direct answers on the state of the art in their fields of research. The second utility level is automatic plagiarism detection and generation of a review article in a specific research area. Lastly, the third utility level is the role of an essential intermediate platform between the researcher and the semantic network.

\section{Ontology-based design science (ODSR) framework for IS research}

We have argued in this paper, so far, the need for accumulation and evolution of knowledge in design science research. Moreover, we have argued for the usefulness of combining DSR and the research ontology engineering. The previous research has established fundamental steps for applying ontology engineering into design science research [30, 36, 37]. For instance, Reiterer et al. [36] describes the "ontology model of DSR aspects of DSR document core ontology (DSRDCO)". The model can be used for supporting search and automatic summarization of DSR publications. There is As a result, we propose a new approach to DSR by adopting the idea of scientific research based on sematic web by Ghanem [9]. By incorporating the existing frameworks for DSR [14] and ontology development in IS research [21, 41], we develop a ODSR framework for understanding, executing and evaluating research following this approach. Figure 1 shows an ontology-based design science (ODSR) framework for IS research.

The ODSR framework demonstrates an iterative process of conducting DSR activities and ontology engineering. The main activities of DSR in this framework are adopted from Hevner et. al. [14] and Nunamaker et. al. [26], including Observation, Construction, and Evaluation. Both of environment constructs and knowledge base can be represented by appropriate ontologies. For instance, there are published studies specifying ontologies of newly emerged research contexts such as an enterprise ontology of business process crowdsourcing [40], or an ontology of learning analytics [25]. The central four activities of ontology engineering are 1) the identification of scope and purpose, 2) ontology development, 3) evaluation, and 4) documentation

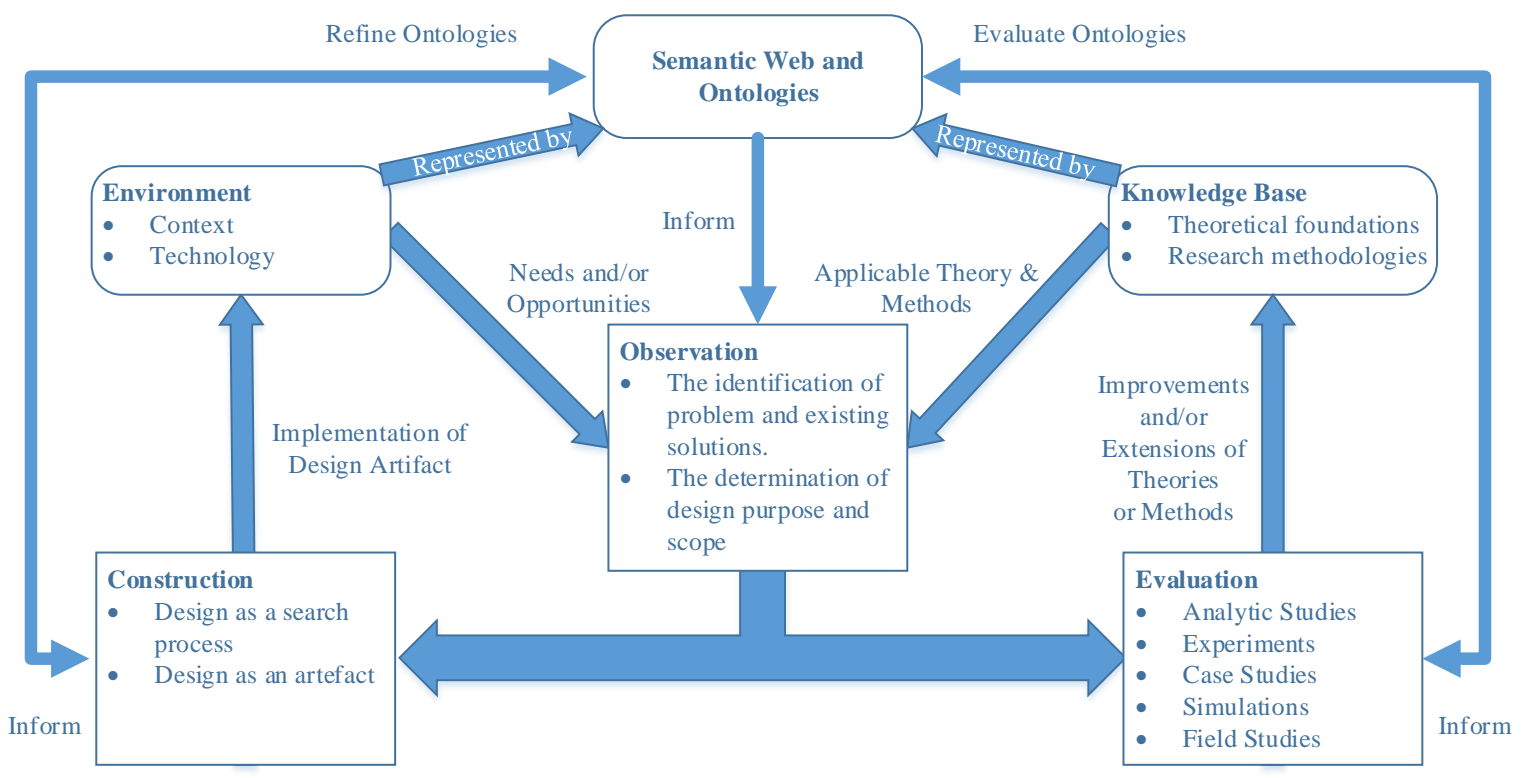

Figure 1: Ontology-based design science (ODSR) framework for IS research 
[41]. The detailed steps of ontology engineering include specification, acquisition, formalization, population, evaluation, and maintenance. [21]. Accordingly, ODSR shows how the ontology engineering activities can be integrated into design science research. The scope and granularity of the ontologies is specified according to the identification of the observed research problem or opportunity. During the construction and evaluation of the DSR artefact, the researchers conduct ontology development to update and refine the existing ontologies. The collaborative and integrated ontologies would be continuously maintained by the research communities that adopt this ODSR approach for conducting research. Overall, DSR and ontology engineering activities are integrated to close the loop between retrieving information to conduct research, constructing and evaluating the DSR artefacts, representing and communicating the research findings.

\section{ODSR Roadmap and guidelines}

Although DSR is now widely used in IS research, lack of a comprehensive and detailed roadmap for Design Science Research (DSR) in the Information System (IS) discipline has been one of the main issues $[3,8]$. As we have argued for a new approach to DSR in IS, this section provides a detailed roadmap and guidelines for conducting and evaluating design DSR following our proposed method. The roadmap was designed based on the review of existing DSR processes, roadmaps and guidelines [8, 14, 30]. Figure 2 demonstrates the ontology-based design science (ODSR) roadmap. The ODSR roadmap consists of eight key steps and four activities connecting the research tasks with the use of ontologies.

Step 1: The first step is to observe and analyse the problem or opportunity in the environment. This step is described as observation activities in Nunamarker et. al.'s multimethodological design research framework [26], the identification of business needs, applicable theory and methods in Hevner et. al.'s DSR framework [14]. In this step, the researchers assess the existing ontologies of relevant technologies and/or theories for identifying the business needs or gaps in the literature [2].

Step 2: The second step is to formally define the

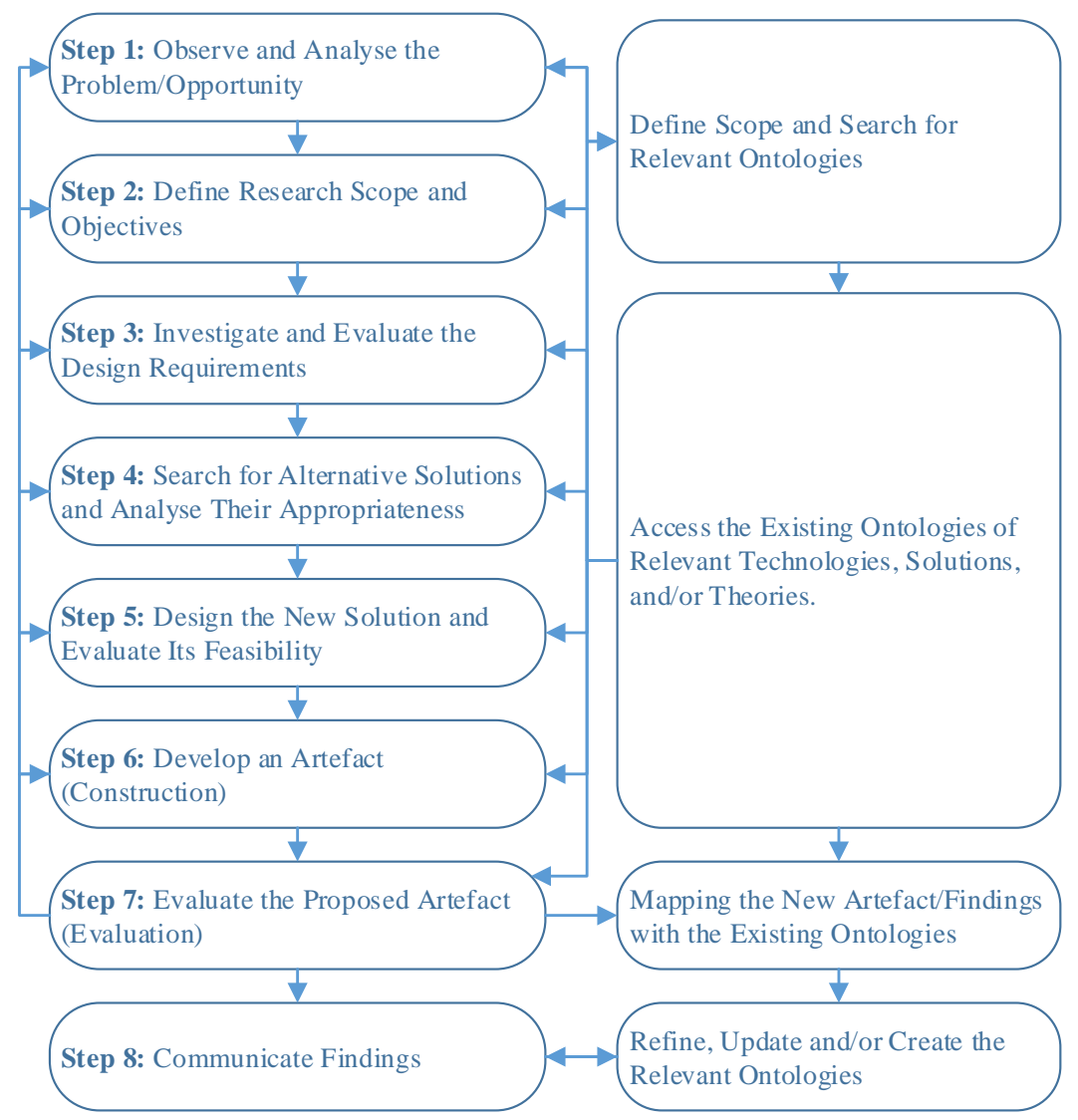

Figure 2: Ontology-based design science (ODSR) Roadmap 
research scope and objectives. While defining the research scope and objectives for the design project, the ontological scope and existing ontologies should be also selected for supporting the research and evaluation process. The selected ontologies should include not only those related to the to-be-built artefacts, but also the semantic representation of publications in the domain of interest. For instance, the DSR researcher can select the ontological representation of design science research publications by Reiterer, Emanuel, and Venable [36] proposes, or the ontology of scientific research by Ghanem et al. [9].

Step 3: The existing ontologies aid the identification of design requirements. The requirements may be adopted from previous studies and practices or constructed for a new context that has not been reported in the literature.

Step 4: Design is "a search process to discover an effective solution to a problem" [14]. It is important to recognize and evaluate the existing solutions before developing a new one. Recently, IS communities have also called for knowledge accumulation and evolution in DSR [32, 38]. By using research ontologies to search for alternative solutions, ODSR limits the risk of plagiarism.

Step 5: In this step, the artefact is designed to address the identified problem/opportunity. As the development of an artefact is a time-consuming process [24, 33], the feasibility of the design is evaluated before conducting the development. The ontologies of existing technologies and theories are used to evaluate the design feasibility.

Step 6: In this step, the researchers start constructing the artefact based on the proposed design. The design requirements, alternative solutions, relevant technologies and theories identified from previous steps should be reflected through the development of the new artefact [3,8].

Step 7: Evaluation is essential in DSR to demonstrate both the relevance to the environment and research significance to the field. In fact, this step helps to distinguish DSR artefacts from practiced-based IT applications [10]. There are various evaluation approaches as such experiments, simulations, case studies or field studies [14]. During the evaluation, the researchers can map the new findings and constructs to the existing ontologies to demonstrate its original contributions to the field.

Step 8: Lastly, the researchers need to communicate the findings with the research communities. In particular, this step involves writing, publishing, and/or presenting research outputs to appropriate academic conferences and journals. Furthermore, the ODSR researchers should refine, update and/or create the relevant ontologies which acts as a shared conceptualization of the constructs and the relations among them within the research field.

\section{Application of ODSR}

To illustrate the application of the ontology-based design science research to DSR, we have selected an exemplar article for analysis. Our goal is not to demonstrate the detailed process of conducting a new study or perform a critical evaluation of the existing research, but rather to illuminate how ODSR could be applied by DSR practitioners for knowledge accumulation and evolution. Hevner et al. [13] notes that the central questions for DSR are "What utility does the new artifact provide?" and "What demonstrates that utility?". The application of ODSR seeks to map the new artifact's utility with the literature and real-world objects, hence provide evidence of contribution.

The selected article is "Development and Validation of a Learning Analytics Framework: Two Case Studies Using Support Vector Machines" by Ifenthaler and Widanapathirana [15]. The article presents the development and validation of a learning analytics framework. Ifenthaler and Widanapathirana evaluate their proposed framework by two case studies using Support Vector Machines, a machine learning approach.

\subsection{Identification of key concepts}

The investigation into relevant ontologies informs researchers about the related elements surrounding the observed problem or opportunity. The domain of interest in this study is the research area of learning analytics and its conceptual frameworks. The review of relevant ontologies leads to the ontology of learning analytics by Nguyen, Gardner and Sheridan [25]. This ontology of learning analytics has been designed as "a knowledge management tool and an encyclopedic reference tool for those who are interested in learning analytics". The development of this ontology also integrated two other ontologies, namely the fourlayered integrated learning ontology by Chung et al. [6] and the publication ontology for scientific research based on semantic web by Ghanem et al. [9]. The inspection of the ontology schema informs the key concepts related to the study. In this case, the fundamental elements of learning analytics are identified by Nguyen, Gardner and Sheridan as Stakeholders, Objectives, Environments, Data, and Instruments [25]. 


\subsection{Information on the state of the art in the relevant fields of research}

The relevant ontologies can support researchers by direct answers on the current literature and real-life objects in the domain of interest [9, 37]. For instance, we can query the learning analytics frameworks to validate the research problem observed by Ifenthaler and Widanapathirana [14], a lack of elaborated and empirically validated frameworks for learning analytics in higher education. Furthermore, this research also argues that the existing learning analytics frameworks do not address the connection between learner characteristics, learning behavior, and curricular requirements. An example SPARQL query can be:

SELECT ?articleTitle

WHERE \{

?article sr:title ?articleTitle

?article sr:keyworld ?keyworld

?article sr:type ?output_type

?keyword rdf:type sr:learning_analytics

?output_type rdf:type sr: framework \}

The result of the query list all studies that propose learning analytics frameworks. The researcher can analyze the problem more deeply by querying all related components included in each framework. In this case, the analysis of the query results verifies the problem observed by Ifenthaler and Widanapathirana. Furthermore, Ghanem et al. [9] proposes that the application of ontologies allows for automatic generation of literature review in a specific domain.

\subsection{Semantic detection of plagiarism}

It is common for young researchers to expend much effort in a study before discovering that the identical research had already been published by other researchers $[9,30]$. To address this issue, a semantic web of publications allows for the detection of plagiarism. By mapping and comparing the breakdown components of an idea with those in the existing articles, ODSR helps to avoid potential plagiarism without being aware of it. As Ifenthaler and Widanapathirana address a theoretical research gap within the field of learning analytics, the above validity of the research problem also benefits the detection of plagiarism. Furthermore, a careful detection is performed with additional queries for detailed information. For instance, Table 2 demonstrates an example of concept breakdown for the case of Ifenthaler and Widanapathirana. Ontological queries to find similar articles with identical concepts indicate the existence of similar studies. Although there are different learning analytics frameworks found in the existing studies, there is no result for matching learning analytics framework applying case studies using Support Vector Machines for evaluation.

\section{Table 2: An example of concept breakdown in ODSR}

\begin{tabular}{|l|l|l|}
\hline Class & Subclass & Instance \\
\hline $\begin{array}{l}\text { Domain of } \\
\text { interest }\end{array}$ & $\begin{array}{l}\text { Educational } \\
\text { Technology }\end{array}$ & Learning Analytics \\
\hline Output type & Artefact & Framework \\
\hline $\begin{array}{l}\text { Evaluation } \\
\text { method }\end{array}$ & Case studies & $\begin{array}{l}\text { Case studies using } \\
\text { Support Vector } \\
\text { Machines }\end{array}$ \\
\hline Instrument & $\begin{array}{l}\text { Analytic } \\
\text { Techniques }\end{array}$ & $\begin{array}{l}\text { Support Vector } \\
\text { Machines; Prediction; } \\
\text { Regression; Natural } \\
\text { language processing }\end{array}$ \\
\hline Stakeholder & $\begin{array}{l}\text { Student; Tutor; Teacher; Governance; } \\
\text { Institution }\end{array}$ \\
\hline Objective & $\begin{array}{l}\text { Explore different approaches for data } \\
\text { analysis for learning analytics; } \\
\text { determine the validity of learning } \\
\text { analytics profiles }\end{array}$ \\
\hline Environment & $\begin{array}{l}\text { Online learning environment; Social } \\
\text { web }\end{array}$ \\
\hline Data & $\begin{array}{l}\text { Physical data; Structure data; } \\
\text { Unstructured data }\end{array}$ \\
\hline
\end{tabular}

\subsection{Establishing contribution to the fields}

Contribution to knowledge has been the foremost criterion for the research publication [10]. It is often a challenge for researchers to differentiate their studies from previous work and demonstrate the original contribution to the fields. ODSR allows for an explicit illustration of original contribution by comparing the new components and relations in the concept breakdown with the existing ontologies representing knowledge in the research fields. In the case of Ifenthaler and Widanapathirana, there is no instance found with the relation between the instance "framework" as an "artefact" and "case studies using Support Vector Machines" as the "evaluation method" in the learning analytics domain. The non-existence of the relation supports the claim of contribution that the study provides a "elaborated and empirically validated framework" for learning analytics.

\subsection{Communicating research findings}

Previous research has noted that it is important but difficult to systematically structure knowledge for DSR 
artefacts [30, 36, 37]. The ontology engineering steps in ODSR can lead to collaborative efforts in formally construct the knowledge base for DSR studies and their artefacts. Consistent with our point of view, Osterwalder, Helfert, and Gama [30] show that the application of ontology engineering process in design science research improves representational information quality of DSR artefacts. Similarly, Reiterer, Emanuel, and Venable [36] demonstrates that a design of a formal DSR ontology can represent the essential semantics of the DSR results. Thus, we argue that ODSR supports researchers to communicate their research findings by mapping them to the collaborative integrated ontologies which represent the units of knowledge for DSR studies and artefacts. In the case of Ifenthaler and Widanapathirana, the original findings can be demonstrated to the ODSR community by adding new components to the learning analytics ontology designed by Nguyen, Gardner and Sheridan [25]. The components are a new instance of class "article" with the relation between the instance "framework" as an "artefact" and "case studies using Support Vector Machines" as the "evaluation method". The amendment of new findings and publications to the shared ontologies allows for establishing a common knowledge structure for design science research.

\section{Conclusion}

This paper aimed at introducing a new approach to design science in IS research, an ontology-based design science research. Ontology engineering has been used as a mechanism for knowledge manage for many years. This paper has revised the issues faced by DSR researchers and the current call for action with DSR community. While DSR has already gained significant interest in IS research, it so far has remained a challenge to evaluate design studies and review background knowledge. We argue that the processes and values of DSR and ontology engineering could be integrated to consolidate each other.

This paper argues that integrating DSR with research ontology engineering could be a significant step forward the collaborative innovation and knowledge accumulation in IS research. Hence, we have proposed a framework for understanding and applying the ontology-based design science approach in IS research. The implementation of this method can reveal missing parts of the existing body of knowledge, and leverage contributions into design science research paradigm in information systems.

However, one may argue that ODSR may require much investment in time and efforts as it involves both activities of design science and ontology engineering.
As mentioned, the use of ontologies can provide considerable help throughout the process of analysis, design, development and evaluation in DSR. This provision of ODSR can not only improve the research quality but also save time and effort for DSR. Furthermore, communicating research outputs for collaborative innovation has been also a timeconsuming process $[4,20]$ and ODSR can foster such communication of ideas and concepts among researchers.

This paper argues for ontology-based design science research, its potential and a case-study based illustration of application, but no actual ODSR has been demonstrated in this paper. Naturally, this is a limitation of the paper. Nevertheless, an ODSR has been carried out in practice by the authors and, in the future, the ODSR will definitely be introduced to IS community. Other researchers are also encouraged to apply and evaluate ODSR in different contexts. We believe that a movement towards ODSR will help move the discipline forward by nurturing knowledge gathering and evolution.

\section{References}

[1] Albani, A., and J.L.G. Dietz, "Enterprise ontology based development of information systems", International Journal of Internet and Enterprise Management 7(1), 2011, pp. 41. [2] Almeida Biolchini, J.C., P.G. Mian, A.C.C. Natali, T.U. Conte, and G.H. Travassos, "Scientific research ontology to support systematic review in software engineering", Advanced Engineering Informatics 21(2), 2007, pp. 133-151. [3] Alturki, A., G. Gable, and W. Bandara, "The Design Science Research Roadmap: In Progress Evaluation", PACIS 2013 Proceedings, 2013.

[4] Baldwin, C., and E. Hippel, "Modeling a paradigm shift: From producer innovation to user and open collaborative innovation", Organization Science 22(6), 2011, pp. 13991417.

[5] Baskerville, R., and J. Pries-Heje, "Explanatory Design Theory", Business \& Information Systems Engineering 2(5), 2010, pp. 271-282.

[6] Chung, H., S. Lee, and J. Kim, "Learning concept sequencing through semantic-based syllabus design and integration”, Indian Journal of Science and Technology, 2015.

[7] Dietz, J.L.G., Enterprise ontology : theory and methodology, Springer, 2006.

[8] Gazem, N., A.A. Rahman, F. Saeed, and N.A. Iahad, "Design Science Research Roadmap Model for Information Systems Projects", International Journal of Information Technology Project Management 9(3), 2018, pp. 1-19.

[9] Ghanem, M., A. Mouloudi, and M. Mourchid, "Towards a scientific research based on semantic web", Procedia Computer Science 73, 2015, pp. 328-335.

[10] Gregor, S., and A.R. Hevner, "Positioning and presenting design science research for maximum impact", MIS quarterly 37(2), 2013, pp. 337-355. 
[11] Guarino, N., "Formal ontology and information systems", Proceedings of FOIS, (1998), 81-97.

[12] Guba, E.G., and Y.S. Lincoln, "Competing paradigms in qualitative research", Handbook of qualitative research 2(163-194), 1994, pp. 105.

[13] Hevner, A.R., and S.T. March, "The information systems research cycle", Computer 36(11), 2003, pp. 111113.

[14] Hevner, A.R., S.T. March, J. Park, and S. Ram, "Design science in information systems research", MIS quarterly 28(1), 2004, pp. 75-105.

[15] Ifenthaler, D., and C. Widanapathirana, "Development and validation of a learning analytics framework: Two case studies using support vector machines", Technology, Knowledge and Learning 19(1-2), 2014, pp. 221-240. [16] Iivari, J., and J. Venable, “Action research and design science research-seemingly similar but decisively dissimilar", 17th European Conference on Information Systems, (2009), 1-13.

[17] Iivari, N., and K. Kuutti, "Towards Critical Design Science Research”, ICIS 2017 Proceedings, 2017. [18] Järvinen, P., "Action research is similar to design science", Quality \& Quantity 41(1), 2007, pp. 37-54. [19] Jones., D., and S. Gregor, "The Anatomy of a Design Theory", Journal of the Association for Information Systems 8(5), 2007.

[20] Kvan, T., "Collaborative design: what is it?", Automation in Construction 9(4), 2000, pp. 409-415. [21] Li, Z., V. Raskin, and K. Ramani, "A Methodology of Engineering Ontology Development for Information Retrieval", International Conference on Engineering Design, (2007).

[22] Lim, E.H.Y., J.N.K. Liu, and R.S.T. Lee, Knowledge seeker: ontology modelling for information search and management : a compendium, Springer, 2011.

[23] Myers, M.D., and J.R. Venable, "A set of ethical principles for design science research in information systems", Information \& Management 51(6), 2014, pp. 801809.

[24] Nelson, H.G., and E. Stolterman, The design way: Intentional change in an unpredictable world, The MIT Press, 2012.

[25] Nguyen, A., L. Gardner, and D. Sheridan, "Building an ontology of learning analytics", Pacific Asia Conference on Information Systems (PACIS) 2018 Proceedings, (2018).

[26] Nunamaker Jr, J.F., M. Chen, and T.D.M. Purdin, "Systems development in information systems research", Journal of management information systems 7(3), 1990, pp. 89-106.

[27] Orlikowski, W.J., and D. Robey, "Information technology and the structuring of organizations", Information systems research 2(2), 1991, pp. 143-169.

[28] Österle, H., J. Becker, U. Frank, et al., "Memorandum on design-oriented information systems research", European Journal of Information Systems 20(1), 2011, pp. 7-10.

[29] Osterwalder, A., and Y. Pigneur, “An ontology for eBusiness models", In Value Creation from E-Business Models. Elsevier, 2004, 65-97.

[30] Ostrowski, L., M. Helfert, and N. Gama, "Ontology engineering step in design science research methodology: a technique to gather and reuse knowledge", Behaviour \& Information Technology 33(5), 2014, pp. 443-451. [31] Papas, N., R.M. O'Keefe, and P. Seltsikas, “The action research vs design science debate: reflections from an intervention in eGovernment", European Journal of Information Systems 21(2), 2012, pp. 147-159.

[32] Peffers, K., T. Tuunanen, and B. Niehaves, "Design science research genres: introduction to the special issue on exemplars and criteria for applicable design science research", European Journal of Information Systems 27(2), 2018, pp. 129-139.

[33] Peffers, K., T. Tuunanen, and M. Rothenberger, "A design science research methodology for information systems research”, Journal of Management Information System, 2007. [34] Raad, J., and C. Cruz, "A Survey on Ontology Evaluation Methods", Proceedings of the 7th International Joint Conference on Knowledge Discovery, Knowledge Engineering and Knowledge Management, SCITEPRESS Science and and Technology Publications (2015), 179-186. [35] Rai, A., "Editor's Comments: Diversity of Design Science Research", Management Information Systems Quarterly 41(1), 2017, pp. iii-xviii.

[36] Reiterer, E., and J.R. Venable, "Ontological support for the use of design science research results", International Conference on Design Science Research in Information Systems and Technology (DESRIST), DESRIST 2016 (2016).

[37] Reiterer, E., J.R. Venable, and T. Reiners, "Ontological representation of design science research publications", DESRIST 2015 (2015).

[38] Sarker, S., S. Gregor, K. Lyytinen, S. Jarvenpaa, and P. Ein-Dor, "Accumulation and Evolution of Knowledge in Design Science Research", Journal of the Association for Information Systems, 2017.

[39] Studer, R., V.R. Benjamins, and D. Fensel, "Knowledge engineering: Principles and methods", Data \& Knowledge Engineering 25(1-2), 1998, pp. 161-197.

[40] Thuan, N.H., P. Antunes, D. Johnstone, and H.X. Son, "Building an enterprise ontology of business process crowdsourcing: A design science approach", PACIS 2015 Proceedings, 2015.

[41] Uschold, M., and M. King, "Towards a methodology for building ontologies", IJCAI95 Workshop on Basic Ontological Issues in Knowledge Sharing, 1995.

[42] Vaishnavi, V., and B. Kuechler, "Design science research in information systems", Association for Information Systems, 2005.

[43] Vaishnavi, V., and W. Kuechler, Design science research methods and patterns: innovating information and communication technology, Taylor \& Francis Group, Boca Raton, FL.

[44] Winter, R., "Design science research in Europe", European Journal of Information Systems 17(5), 2008, pp. 470-475.

[45] Yin, R.K., Case study research: Design and methods, Sage publications, 2013.

[46] Zouaq, A., S. Joksimovic, and D. Gasevic, “Ontology learning to analyze research trends in learning analytics publications.", LAK (Data Challenge), 2013. 